\title{
Evaluation of Decalcified Teeth Sections by Routine Processing \& Hot Air Oven Technique
}

Aruna Kumari Maloth ${ }^{1}$, Shyam Prasad Reddy Dorankula², Keerthi Muddana ${ }^{3}$, Pavan G kulkarni ${ }^{4}$, Nandan SRK ${ }^{5}$

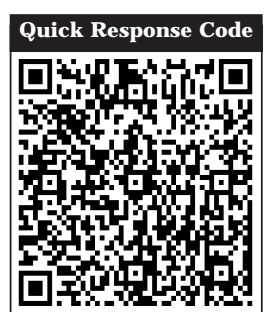

doi: $10.5866 / 2016.8 .10010$

${ }^{1}$ Senior Lecturer

${ }^{2 \& 4}$ Reader

3Senior Lecturer

Department of Oral Pathology,

Kamineni Institute of Dental Sciences,

Nalgonda-508254,Telangana State.

${ }^{5}$ Professor and Head

Kamineni Institute of Dental Sciences,

Nalgonda-508254, Telangana State

\section{Article Info:}

Received: J anuary 10, 2016

Review Completed: February 9, 2016

Accepted: March 13, 2016

Available Online: May, 2016 (www.nacd.in)

(C) NAD, 2016 - All rights reserved

\section{Email for correspondence:}

dr.arunaopath@gmail.com

\begin{abstract}
:
Context: Decalcification is the process of removing calcium salts from tissues. Calcified tissue must be decalcified before processing as the tissue cannot be sectioned. Though some agents remove the calcium ions completely and rapidly, they adversely affect the staining characteristics and may also damage the organic components.
\end{abstract}

Aim: The present study was to evaluate the estimation rate of decal cification of four different decal cifying agents and comparision with $\mathrm{H}$ ot air oven technique.

Materials and methods: Four decalcifying agents namely, neutral ethylene diamine tetra acetic acid (EDTA), nitric acid, formic acid, and combination of formic acid and HCL were used to decalcify 24 natural teeth (three in each solution).The end point of decalcification was evaluated. The decalcified teeth were then routinely processed, sectioned, and stained with hematoxylin and eosin stains.

Results: Rate of Decalcification was faster with Hot air oven when compared with Manual procedure among all decalcifying agents. Soft tissue integrity was better with combination of formic acid and $\mathrm{HCL}$ as decalcifying agent compared with others.

Condusion: In the present study, it was observed that the rate of decalcification was faster with hot air oven when compared with manual procedure among all decalcifying agents. Regardless of employed technique, soft tissue integrity was better with combination of formicacid and HCL as decalcifying agent compared with others.

Key words: decalcification, teeth, hot air oven technique.

\section{INTRODUCTION}

Teeth belong to the category of hardest tissues due to its enamel, which is highly mineralized and chemically more inert when compared to other body tissues. Microscopic examination of teeth is very difficult because of large amounts of inorganic components like calcium, phosphorus and biological apatite. The complex tooth structure and extraordinary hardness of enamel makes this organ very difficult to process and section for observation under microscope. ${ }^{1}$

Various decalcifying agents have been used in 
the past. The decalcifying solutions are selected based on following parameters, rate of decalcification and the effect of decalcifying agents on the tissue and its staining characteristics. ${ }^{2}$ So, an ideal decalcifying agent should be fast, be good and do good. So, we present here the comparative evaluation of different decalcifying agents with respect to rate of decalcification (manual vs hot air oven technique), the effect of decalcifying agents on speed of decalcification, soft tissue integrity, and staining quality.

The aims and objectives of the study were:

1. To compare methods for decal cifying teeth (Hot air oven vs Routine)

2. To evaluate efficacy of various chemicals for decalcification of human teeth by various methods.

3. To compare decalcified teeth sections, routine tissue processing vs hot air oven technique.

\section{MATERIALS \& METHODS}

\section{Sample collection}

Freshly extracted, non carious, not attrited, 24 natural teeth were obtained from patients aged 3545 years. The teeth, fixed in $10 \%$ formal in, included premolars and molars which were used to analyze the four different decal cifying agents namel y neutral ethylene diamine tetra acetic acid (EDTA), nitric acid, formic acid, and combination of formic acid and $\mathrm{HCL}$ (three in each solution).

\section{Decalcification}

Decalcifying agents were subjected to repeated agitation and replaced by freshly prepared agents. In the manual decal cification procedure, the solution was changed once in 3 days and the $\mathrm{pH}$ and temperature were recorded on a daily basis. In the hot air oven technique, the teeth were kept for three cycles of 4 hours each per day and checked in between for formic acid, nitric acid, combination of formic acid and HCL and EDTA. The temperature of all four decalcifying solutions was maintained at around $80-100^{\circ} \mathrm{C}$. The decalcifying solution was changed every day and the end-point was ascertained on a daily basis using the calcium oxalate method (Clayden 1952). ${ }^{3}$

\section{Tissue processing and staining}

After ensuring complete decalcification, all the teeth were washed using distilled water for $30 \mathrm{~min}$, following which they were continued with routine processing, paraffin wax infiltration, and embedding; sectioning and staining with hematoxylin and eosin. The speed of decalcification was graded from 1-5 [1-slowest and 5-fastest]. The stained sections were observed under the microscope and were graded from 1-4 [1-poor, 2-fair, 3-good, and 4-excellent] based on the following criteria. ${ }^{2}$

1. Ease of sectioning;

2. Hard-tissue staining;

3. Soft-tissue staining - both cytoplasmic and nuclear staining;

4. Soft-tissue attachment;

5. Soft-tissue shrinkage and;

6. Pulpal organization

\section{RESULTS}

Parameter 1, Speed of decalcification: 5\% nitric acid decalcified the tooth fastest and neutral EDTA was slowest. (Table 1: Time in days taken for decalcification by manual and hot air oven)

Parameter 2, Soft tissue integrity: With respect to soft tissue integrity, teeth decalcified with combination of formic acid and hydrochloric acid exhibited excellent results. (Table 2: Soft tissue integrity by manual and hot air oven)

Parameter 3, Staining quality: Teeth decalcified with combination of formic acid and hydrochloric acid stained the best. (Table 3: Staining characteristics by manual and hot air oven).

Overall speed of decalcification was faster with hot air oven technique compared to the manual process. Among the decalcifying agents $5 \%$ nitric acid decalcified faster compared to other agents. whereas soft tissue integrity and staining quality was excellent with combination of formic acid and hydrochloric acid in both hot air oven technique and manual process (Table 4).

\section{DISCUSSION}

Decalcification of hard tissue is one of the most sensitive technique in the histopathology laboratory. It is the one of the significant method in oral pathology as decalcification of bone and teeth is a routinely required procedure. ${ }^{4,5}$ The process of decalcification is very important in the preparation of oral calcified tissues for microscopic examination. It is important because of two standpoints: firstly, 


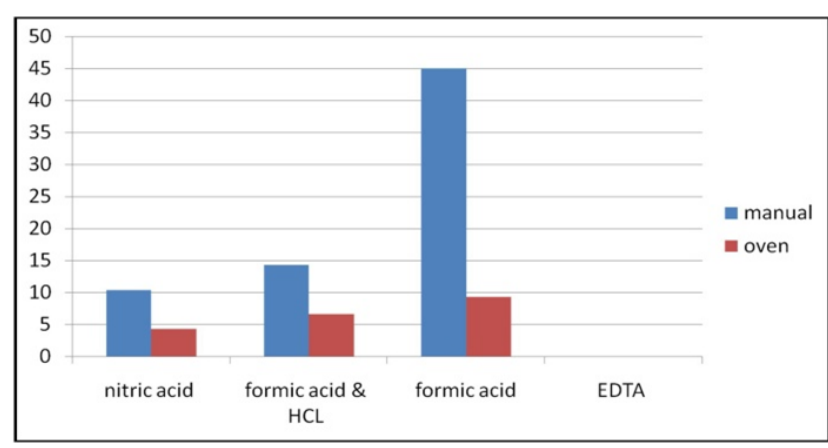

Table 1: Time in days taken for decalcification by manual and hot air oven technique

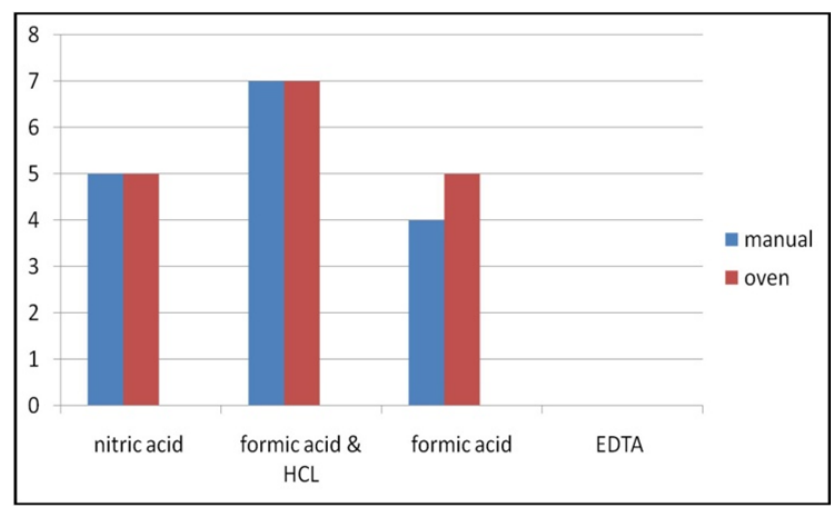

Table 3: Staining characteristics by manual and hot air oven technique

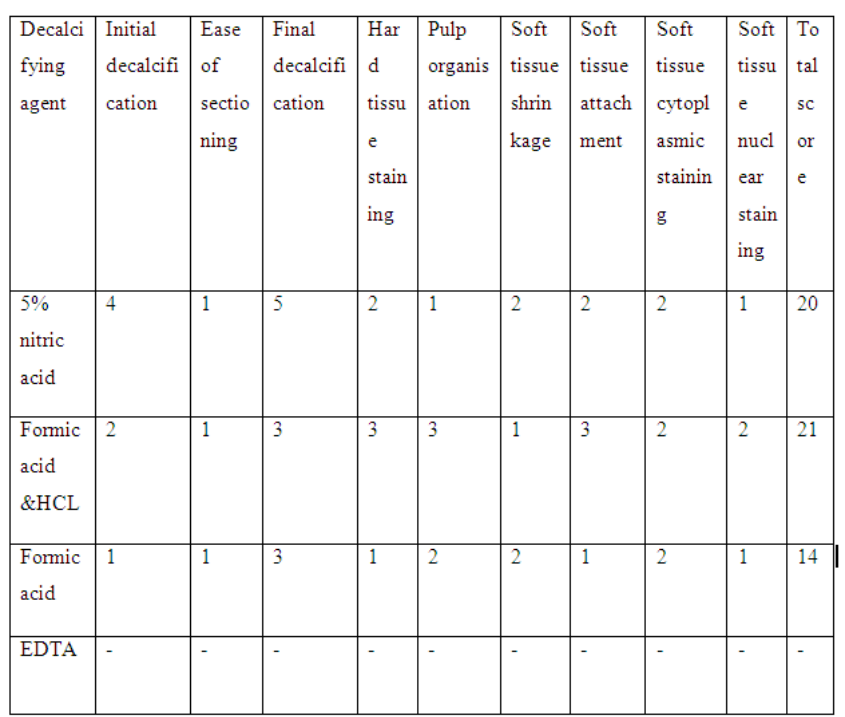

Table 4: Cumulative scores of the decalcifying agents based on various parameters.

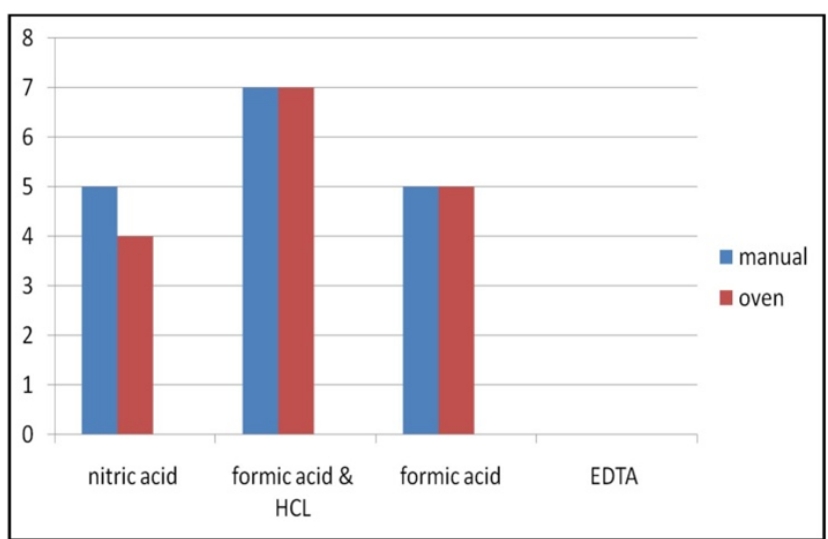

Table 2: Soft tissue integrity by manual and hot air oven technique

sections of teeth, bone, and surrounding tissues are difficult to obtain without removal of the calcium; and secondly, the effect of the various chemical decal cifying agents on the tissue components differ. ${ }^{6}$ Fixation is the first step for the preparation of hard teeth tissues. ${ }^{7}$

For many years, scientists have tried to introduce new decalcifying agents or tried to modify known decalcification agents, ${ }^{8}$ in order to meet the criteria of a good decal cifying agent which

i. Ensures complete removal of calcium;

ii. Causes minimal damage to cells and tissues;

iii. Causes non impairment to subsequent staining and;

iv. Decalcifies at reasonable speed..$^{9}$

In the present study, an attempt was made to compare the methods for decalcifying teeth and evaluation of efficacy of various chemicals for decalcification of human teeth by various methods.

A new method using hot air oven was seen to accelerate the rate of decalcification. The choice of decalcifying agent and method depends on the urgency of the procedure. ${ }^{10}$ In the present study speed of decalcification was faster with hot air oven when compared to manual process. Among the decalcifying agents, 5\% nitric acid decalcified highest and lowest by neutral EDTA decalcifying solution. Pitolet al, (2007) showed that there was a 30 -fold increase in decalcification speed compared to the traditional method when the material was irradiated in a microwave oven. ${ }^{11}$ 
In terms of efficacy of agents with respect to the soft-tissue integrity and hard- and soft-tissue staining, in the present study excellent results were actually obtained with combination of formic acid and hydrochloric acid. Zappa et al, ${ }^{1}$ suggested that formic acid and nitric acid produce worst results. In contrast in the present study formic acid and $\mathrm{HCL}$ combination gave good results as it showed minimal soft-tissue shrinkage and minimal loss of tissue.

The overall superior results were obtained with combination of formic acid and HCL. The overall histological impression in the hot air oven method compared to routine method was significantly better.

\section{CONCLUSION}

In the present study, it was observed that, rate of decalcification was faster with hot air oven when compared with manual procedure and $5 \%$ nitric acid decalcified faster compared to all other decalcifying agents. Regardless of empl oyed technique, soft tissue integrity was better with combination of formic acid and HCL as decal cifying agent when compared with others.

\section{REFERENCES}

1. Zappa J, Cieslik Bielecka A, Adwenti M, Cieslik T: Comparison of different decalcification methods to hard teeth tissues morphological analysis. Dent Med Probl 2005; 42(1):21-6.

2. Karpagaselvi Sanjai, J ayalakshmi Kumarswamy, Archana Patil, Lokesh Papaiah, Srinivas J ayaram, Lakshmi Krishnan. Evaluation and comparison of decalcification agents on the human teeth. J Oral Maxillofac Pathol 2012; 16(2):212-27.
3. Callis GM, Bancroft J D. Theory and Practice of Histological Techniques. $6^{\text {th }}$ ed.E dinburgh: Churchill Livingstone 2008 pg. 338-60.

4. Bhaskar SN. Orban's Oral Histology and Embryology. $10^{\text {th }}$ ed. New Delhi: CBS Publishers and Distributors 1990 pg 349-54.

5. R Sangeetha, K Uma, Vidya Chandavarkar. Comparison of routine decalcification methods with microwave decalcification of bone and teeth. J Oral Maxillofac Pathol 2013; 17(3).

6. Morse A: Formic acid- Sodium Citrate Decalcification and Butyl Alcohol dehydration of teeth and bones for sectioning in teeth and bones for sectioning in paraffin. J Dent Res 1945; 24:143-53.

7. Mawhinney WHB, Richardson E, Malcolm AJ. Technical methods control of rapid nitric. J Clin Pathol 1984; 37:140915.

8. Callis MG. Bone. In: Bancroft J D, Gamble M, editors. Theory and practice of histological techniques. $6^{\text {th }}$ ed. Philadel phia: Churchill Livingstone 2008 pg 333-63.

9. Culling CF, Allison RT, Barr WT. Cellular pathology technique. $4^{\text {th }}$ ed. London: Butterworths 1985 pg 408-30.

10. De-Deus G, Reis C, Fidel S, Fidel RA, Paciornik S. Longitudinal and quantitative evaluation of dentin demineralization when subjected to EDTA, EDTAC, and citric acid: A co-site digital optical microscopy study. Oral Surg Oral Med Oral Pathol Oral Radiol Endod 2008; 105:391-7.

11. Pitol DL, Caetano FH, Lunardi LO. Microwave induced fast decalcification of rat bone for electron microscopic analysis: An ultrastructural and cytochemical study. Braz Dent J 2007; 18:153-7.

\section{Gain quick access to our journal online View our journal at www.nacd.in}

